\title{
Adduct formation identification between phenyl glycidyl ether and 2'-deoxyadenosine and thymidine by chromatography, mass spectrometry and nuclear magnetic resonance spectroscopy
}

\author{
E. VAN DEN EECKHOUT*
}

University of Ghent, College of Pharmacy, Harelbekestraat 72, B-9000 Ghent (Belgium)

A. DE BRUYN

University of Ghent, Laboratory for Organic Chemistry, Krijgslaan 281, B-9000 Ghent (Belgium)

H. PEPERMANS

Unilever Research Laboratorium Vlaardingen, O. van Noortlaan 120,3133 AT Vlaardingen (The Netherlands)

E. L. ESMANS and I. VRYENS

University of Antwerp (RUCA), Laboratory for Organic Chemistry, Groenenborgerlaan 171, B-2020 Antwerp (Belgium)

J. CLAEREBOUDT and M. CLAEYS

University of Antwerp (U.I.A.), Department of Pharmacy, Universiteitsplein I, B-2610 Wilrijk (Belgium) and

J. E. SINSHEIMER

University of Michigan, College of Pharmacy, Ann Arbor, MI 48109 (U.S.A.)

(First received June 15th, 1989; revised manuscript received October 13th, 1989)

\section{SUMMARY}

Thymidine and $2^{\prime}$-deoxyadenosine were reacted with phenyl glycidyl ether in order to study the formation of the corresponding $2^{\prime}$-deoxynucleoside adducts. Separation methods were elaborated using either reversed-phase high-performance liquid chromatography with photodiode-array detection, or centrifugal circular thin-layer chromatography. The adducts were isolated on a preparative scale and were fully characterized by UV spectroscopy, desorption chemical ionization and fast atom bombardment mass spectrometry and $270-$ and $360-\mathrm{MHz}{ }^{1} \mathrm{H}$ NMR spectrometry. For thymidine the main adduct was characterized as N-3-(2-hydroxy-3-phenoxypropyl)thymidine. With 2'-deoxyadenosine, predominantly N-1-(2-hydroxy-3-phenoxypropyl)-2'-deoxyadenosine was formed. With longer reaction times, the formation of a minor amount of dialkylated $2^{\prime}$-deoxyadenosine was observed. These nucleoside adducts will be used as marker compounds for studies of DNA adduct formation. 


\section{INTRODUCTION}

Mono- and bifunctional glycidyl ethers are widely used for the production of epoxy resins and to improve the processing and stability of industrial polymers. Therefore, their structure-mutagenicity and structure genotoxicity relationships have been the subject of in vitro ${ }^{1-13}$ and in vivo studies ${ }^{2,14-17}$ in order to assess the genotoxic potential of these particular chemicals.

From a review published by Hopkins ${ }^{18}$, it could be concluded that although these compounds were mutagenic, in vitro and in vivo studies needed more emphasis. Further, as it has been reported that workers exposed to glycidyl ethers suffered skin and eye irritation and allergic reactions ${ }^{19}$ and that even adverse testicular and haemopoietic effects have been described ${ }^{20}$, a thorough study of the biological action of these compounds is warranted. The effects described above led in 1978 to recommendations for limiting the occupational exposure to these compounds ${ }^{19}$. It is generally believed that reactions of electrophilic reactants with sites in DNA, RNA or protein are fundamental to the induction of mutations. Our interest in the structuremutagenicity relationships for aliphatic epoxides ${ }^{12,13,21-25}$ and in the reactivity of some of these epoxides with 2 -deoxynucleosides and DNA ${ }^{26-28}$ prompted us to extend the limited literature ${ }^{9,29}$ on the reactivity and identification of adduct formation between phenylglycidyl ethers and 2'-deoxynucleosides.

In this paper we report the separation and structure elucidation of the nucleoside adducts formed between 2 -deoxyadenosine and thymidine with phenyl glycidyl ether. For this purpose, preparative centrifugal circular thin-layer chromatography (TLC) and both analytical and preparative reversed-phase high-performance liquid chromatography (HPLC) were used. On-line identification during HPLC analysis was done by means of a photodiode-array detector, which proved to be a powerful approach for the assignment of the alkylation site. The main adducts isolated were confirmed by means of mass spectrometry (MS) and nuclear magnetic resonance (NMR) spectrometry.

\section{EXPERIMENTAL}

\section{Materials}

All solvents were of analytical-reagent grade. Phenyl glycidyl ether (2,3epoxypropyl phenyl ether) was obtained from Janssen Chimica (Beerse, Belgium), and was distilled in vacuo before use. $2^{\prime}$-Deoxyadenosine (dAdo) and thymidine (Thy) were purchased from Sigma (St. Louis, MO, U.S.A.). 3-Phenoxypropane-1,2-diol was synthesized as reported ${ }^{30}$.

\section{Reaction of $2^{\prime}$-deoxynucleosides with phenyl glycidyl ether}

Thymidine or 2'-deoxyadenosine ( $2 \mathrm{mg}$ ) was dissolved in $2 \mathrm{ml}$ of methanol and $1 \mathrm{ml}$ of $1 M$ phenyl glycidyl ether in methanol was added. The compounds were allowed to react for 24 or $48 \mathrm{~h}$ at $37^{\circ} \mathrm{C}$ in tightly scaled test-tubes cquipped with a PTFE-lined screw-cap. For preparative purposes $50 \mathrm{mg}$ of $2^{\prime}$-deoxynucleoside in methanol were used. 


\section{Thin-layer chromatography}

TLC was performed on silica gel $60 \mathrm{GF}_{254}$, thickness $0.25 \mathrm{~mm}(10 \mathrm{~cm} \times 10 \mathrm{~cm}$ plates) (E. Merck, Darmstadt, F.R.G.). The following solvent systems were used as mobile phases: (I) dichloromethane-methanol (90:10); (II) dichloromethane-methanol (60:20); (III) butanol-acetone-acetic acid-water (10:10:2:5); (IV) dichloromethane-tetrahydrofuran (THF) (20:80); and (V) isopropanol-ammonia-water $(70: 10: 20)$.

A $10-\mu 1$ volume of the reaction mixture was applied to the plate, together with Thy, dAdo $(1 \mathrm{mg} / \mathrm{ml})$, phenyl glycidyl ether $(1 \mathrm{mg} / \mathrm{ml})$ and phenoxypropane-1,2-diol (1 $\mathrm{mg} / \mathrm{ml}$ ) (synthesized ${ }^{30}$ ) as reference compounds.

\section{Preparative centrifugal circular thin-layer chromatography}

Centrifugal circular TLC was performed on a Chromatotron instrument (Harrison Research, Palo Alto, CA, U.S.A.). Silica gel plates were used with a layer thickness of $2 \mathrm{~mm}$, prepared by suspending $65 \mathrm{~g}$ of Kieselgel $60 \mathrm{P} \mathrm{F}_{254}$ (E. Merck) in $130 \mathrm{ml}$ of distilled water.

Analysis of the thymidine-phenyl glycidyl ether reaction mixture. The mobile phase was dichloromethane-THF $(30: 70)$ at a flow-rate of $7 \mathrm{ml} / \mathrm{min}$. For samples preparation, after reaction 24 or $48 \mathrm{~h}$ (see above), the methanol was removed under reduced pressure and the residue was dissolved in $1.1 \mathrm{ml}$ of THF containing 3 drops of methanol. The amount injected was $1.0 \mathrm{ml}$.

Under these conditions and with both reaction times, three compounds eluted, with $R_{F}$ values from analytical TLC on silica gel of $0.95,0.80$ and 0.70 . The first band, identified as phenyl glycidyl ether, was discarded. The other two compounds were collected, the solvent was removed under reduced pressure and the residues were analysed by NMR and MS. The compound with $R_{F} 0.70$ was identified as thymidine and that with $R_{F} 0.80$ as an adduct.

Analysis of the 2 -deoxyadenosine-phenyl glycidyl ether reaction mixture. The mobile phase was dichloromethane-THF (20:80) at a flow-rate of $7 \mathrm{ml} / \mathrm{min}$. Samples and amounts injected were as for thymidine.

When the reaction was performed for $24 \mathrm{~h}$, four compounds were separated, with $R_{F}$ values from analytical TLC on silicagel of $0.10,0.36,0.80$ and 0.95 . However, when the reaction was performed for $48 \mathrm{~h}$, five compounds were detected, with $R_{F}$ values from analytical TLC on silica gel of $0.10,0.20,0.36,0.80$ and 0.95 .

The bands with $R_{F} 0.36$ (AD-1) and 0.20 (AD-2) were collected. After removal of the solvent under reduced pressure, $\mathrm{AD}-1$ (main compound) was subjected to NMR and desorption chemical ionization (DCI) MS. AD-2 was subjected only to DCI and fast atom bombardment (FAB) MS, as the amount recovered was insufficient for NMR analysis.

\section{Analytical reversed-phase $H P L C$}

Analytical reversed-phase HPLC was done on a chromatograph equipped with a Waters Assoc. M-45 pump and a $20-\mu \mathrm{l}$ six-way Valco valve external loop. Detection was effected with a Hewlett-Packard Model 1040A photodiode-array detector equipped with a Hewlett-Packard Model $8290 \mathrm{M}$ flexible disk drive and HewlettPackard 85 computer.

For the analysis of the thymidine phenyl glycidyl ether and the deoxyaden- 
osine phenyl glycidyl ether reaction mixtures, a 10 RP-18 column $(25 \mathrm{~cm} \times 4.6 \mathrm{~mm}$ 1.D.) (Bio-Rad, Ghent, Belgium) was used. The eluent for the thymidine-phenyl glycidyl ether mixture was $0.01 \mathrm{M}$ ammonium formate (adjusted with formic acid to pH 5.1)-methanol (95:5) at a flow-rate of $2 \mathrm{ml} / \mathrm{min}$. For deoxyadenosine-phenyl glycidyl ether the same eluent was used but in the proportions 90:10, at a flow-rate of $1.8 \mathrm{ml} / \mathrm{min}$. The detection wavelength was $260 \mathrm{~nm}$.

\section{Preparative reversed-phase $H P L C$}

Preparative reversed-phase HPLC was used for the isolation of the main $2^{\prime}$-deoxyadenosine adduct. This was done on the same apparatus as for the analytical separations but with a 10 RP- $18(25 \mathrm{~cm} \times 2.2 \mathrm{~cm}$ I.D. $)$ column (Alltech). The mobile phase was $0.01 \mathrm{M}$ ammonium formate (pH 5.1)-methanol (80:20) at a flow-rate of 7.2 $\mathrm{ml} / \mathrm{min}$. The mixtures after reaction for 24 and $48 \mathrm{~h}$ were injected separately using a six-way Valco valve with a $100-\mu l$ loop. The detection wavelength was $260 \mathrm{~nm}$.

\section{NMR spectrometry}

One-dimensional (1D) ${ }^{1} \mathrm{H}$ NMR spectra were run on a Bruker WH 360 apparatus at $18^{\circ} \mathrm{C}$ with $2 \%$ solutions. A pulse of $2 \mu \mathrm{s}$, quadrature detection and a resolution of $0.208 \mathrm{~Hz}$ per point were used.

A spin-lock experiment ${ }^{31,32}$ was performed on $3 \mathrm{mg}$ of dAdo adduct in $0.4 \mathrm{ml}$ of methanol-water $(1: 1, \mathrm{v} / \mathrm{v})$ at $30^{\circ} \mathrm{C}$ on a Bruker AM 270 spectrometer. The experiment was recorded with the pulse sequence PS- $90^{\circ}-t_{1}-\mathrm{SL}-t_{2}$, SL being a $100-\mathrm{ms}$ spin-lock pulse with $4.0-\mathrm{kHz}$ field strength and PS a 1-s presaturation period on the water signal. The phase of the first pulse was incremented with $t_{1}$ to obtain pure absorption spectra [Time Proportional Phase Increment (TPPI) method] ${ }^{33}$. In a total time of $15 \mathrm{~h}, 256$ interferograms of $1 \mathrm{~K}$ data points were recorded. These were multiplied by a $\pi / 3$ shifted sine-bell, Fourier transformed and phase-corrected. The $t_{1}$ interferograms were multiplied by a $\pi / 3$ sine-bell, zero-filled to $1 \mathrm{~K}$, Fourier transformed and phasecorrected. The digital resolution in both dimensions was $5.8 \mathrm{~Hz}$ per point.

\section{Desorption chemical ionization mass spectrometry}

DCI mass spectra were recorded on a Ribermag 10-10B quadrupole mass spectrometer (Nermag, Paris, France) equipped with a Sidar data system. Primary ionization of the reagent gas (ammonia) was done with the aid of $70-\mathrm{eV}$ electrons. The ionizaton current was $0.08 \mathrm{~mA}$ and the source temperature was $100^{\circ} \mathrm{C}$. The ion source pressure was $0.1 \mathrm{mmHg}$. The compounds were brought onto the DCI probe with a microsyringe. After evaporation of the solvent, the DCI probe was heated at a rate of $9 \mathrm{~mA} / \mathrm{s}$. Spectra were recorded over a mass range of 100-600 u using an integration time of $2 \mathrm{~ms} / \mathrm{u}$. The ion current profile generated during DCI was reconstructed from the total ion current associated with each of the consecutively recorded mass spectra and the mass spectra which were associated with the scan numbers corresponding to the maximum intensity in the reconstructed total ion current profile were plotted for interpretation.

\section{Fast atom bombardment mass spectrometry}

FAB-MS and landem MS (MS-MS) were carried out on a VG 70 SEQ hybrid mass spectrometer (VG Analytical, Winsford, U.K.), controlled through a VG 
11-250 data system. The instrument is equipped with an Ion Tech saddle field atom gun and consists of a high-resolution double-focusing mass spectrometer (MS-I) with EB configuration followed by an radiofrequency (RF)-only quadrupole collision gas cell and a high-performance quadrupole mass analyser, which is used as MS-II. Samples were dissolved in the minimum amount of methanol and a $1-\mu 1$ aliquot was added to the matrix (e.g., glycerol). Fast atom bombardment by a $1-\mathrm{mA}$ beam of 8 -keV xenon atoms was used to desorb ions from the matrix. Spectra were recorded by repetitive scanning over the range $20-600 \mathrm{u}$ using a scan time of $2 \mathrm{~s} /$ decade.

MS-MS or daughter ion spectra were obtained by collisionally activated decomposition (CAD) using argon as collision gas in the third field-free region (RF-only quadrupole collision gas cell) and by scanning MS-II. The FAB-MSCAD-MS spectra were obtained by averaging ten scans.

\section{Ultraviolet spectroscopy}

UV spectra were recorded on-line during HPLC analysis in the HPLC solvent system with the aid of the photodiode-array detector.

UV spectra from preparatively isolated samples such as AD-1 and Th-1 were taken off-line on a Perkin-Elmer Lambda 15 UV-VIS spectrophotometer equipped with a Perkin-Elmer EX-800 printer.

Dried samples were diluted in water to obtain absorbance values between 0.5 and 1.0. UV spectra were recorded at acidic $\mathrm{pH}$ by mixing the aqueous samples with an equal volume of $0.1 M$ hydrochloric acid or at alkaline $\mathrm{pH}$ by mixing with an equal volume of $0.1 \mathrm{M}$ sodium hydroxide solution. Aliquots of preparatively collected fractions were mixed with an equal volume of $12 M$ hydrochloric acid to observe any changes in the UV spectrum $18 \mathrm{~h}$ after addition of the acid.

\section{RESULTS AND DISCUSSION}

Thymidine and $2^{\prime}$-deoxyadenosine were reacted with phenyl glycidyl ether in methanol. After 24 and $48 \mathrm{~h}$ at $37^{\circ} \mathrm{C}$, the resulting reaction mixtures were analysed and the structures of the resulting $2^{\prime}$-deoxynucleoside adducts were elucidated. Phenoxypropane-1,2-diol was formed in minor amounts as a hydrolysis product of phenyl glycidyl ether in some of the reactions.

\section{$H P L C-U V$ spectroscopy}

As it has been shown that nucleoside mixtures are excellent candidates for HPLC analysis, the adduct formation described above was investigated by reversed-phase HPLC using $0.01 M$ ammonium formate ( $\mathrm{pH} 5.1$ )-methanol mixtures as eluents.

The eluted compounds were detected by a photodiode-array detector, which is particularly useful in these analyses as the recording of detailed UV spectra of the compounds in the mixture indicates the location of the alkylated 2 -deoxynucleosides on the HPLC trace. Further, these UV data give a strong indication of the alkylation site on the heterocyclic basc moicty, as supported by the work of Singer $^{34}$, who published a large amount of UV spectral data for nucleosides. She showed that the UV spectra of nucleosides obtained at different $\mathrm{pH}$ values, together with the calculation of the absorbance ratio measured at 254 and $280 \mathrm{~nm}$, provide information on the alkylation site on the heterocyclic base moiety. Our group has used this approach for 
TABLE 1

COMPARATIVE TABLE OF UV SPECTRAL DATA OF ADDUCTS OF THYMIDINE AND DEOXYADENOSINE

\begin{tabular}{|c|c|c|c|}
\hline Adduct & Solvent & $\begin{array}{l}\lambda_{\max } \\
(n m)\end{array}$ & $\begin{array}{l}\text { Ratio, } \\
254 / 280 \mathrm{~nm}\end{array}$ \\
\hline N-3-Ethylthymidine ${ }^{a}$ & $\begin{array}{l}\mathrm{H}_{2} \mathrm{O} \\
\mathrm{pH} 1\end{array}$ & $\begin{array}{l}269 \\
269\end{array}$ & 0.95 \\
\hline $\mathrm{N}$-3-Epichlorohydrin-thymidine ${ }^{b}$ & $\begin{array}{l}\mathrm{H}_{2} \mathrm{O} \\
\mathrm{pH} 1\end{array}$ & $\begin{array}{l}269 \\
269\end{array}$ & 1.00 \\
\hline N-3-Phenyl glycidyl ether - thymidine ${ }^{c}$ & $\begin{array}{l}\mathrm{H}_{2} \mathrm{O} \\
\mathrm{pH} 1\end{array}$ & $\begin{array}{l}269 \\
269\end{array}$ & 1.00 \\
\hline Thymidine $^{c}$ & $\begin{array}{l}\mathrm{H}_{2} \mathrm{O}, \\
\mathrm{pH} \mathrm{i}\end{array}$ & $\begin{array}{l}267 \\
267\end{array}$ & 1.20 \\
\hline N-1-Propylene oxide-deoxyadenosine ${ }^{b}$ & $\begin{array}{l}\mathrm{H}_{2} \mathrm{O} \\
\mathrm{pH} \mathrm{i}\end{array}$ & $\begin{array}{l}259 \\
259\end{array}$ & $\begin{array}{l}2.8 \\
3.1\end{array}$ \\
\hline N-1-Glycidoldeoxyadenosine ${ }^{b}$ & $\begin{array}{l}\mathrm{H}_{2} \mathrm{O} \\
\mathrm{pH} \mathrm{l}\end{array}$ & $\begin{array}{l}258 \\
258\end{array}$ & $\begin{array}{l}2.5 \\
2.5\end{array}$ \\
\hline N-1-Phenyl glycidyl ether-deoxyadenosine ${ }^{c}$ & $\mathrm{H}_{2} \mathrm{O}$ & 261 & 2.4 \\
\hline
\end{tabular}

${ }^{a}$ Ref. 34.

${ }^{b}$ Ref. 27.

${ }^{c}$ Our results.

the identification of $\mathrm{N}-3$-alkylated thymidines formed by the reaction between thymidine and several propylene oxides ${ }^{27}$. The results obtained in these studies, as they pertain to the present study, are summarized in Table I. Comparison with the UV results given by photodiode-array detection coupled with HPLC as summarized in Table II led to the suggestion of N-1 alkylation for $2^{\prime}$-deoxyadenosine and N-3 alkylation for thymidine, as the $254 / 280 \mathrm{~nm}$ ratios of the isolated peaks corresponded to the ratios found by either Singer or our group.

\section{TABLE II}

HPLC CAPACITY FACTORS, UV PEAK MAXIMA AND 254/280 nm ABSORBANCE RATIOS FOR PEAKS FROM THYMIDINE AND DEOXYADENOSINE REACTIONS AS SHOWN IN FIG. 2

\begin{tabular}{lrlll}
\hline Peak & $k^{\prime a}$ & \multicolumn{2}{l}{$\lambda_{\text {max }}(n m)(\text { ratio })^{c}$} \\
\cline { 3 - 5 } & & $0.05 M H C C^{b}$ & $p H 5.1$ & $0.05 M^{\prime} N^{\prime} O H^{b}$ \\
\hline dAdo & 8.5 & $257(4.4)$ & $260(5.9)$ & $260(6.0)$ \\
AD-1 & 19.5 & $261(2.4)$ & $261(2.4)$ & $263(2.1)$ \\
Phenyl glycidyl ether-diol & $23.5^{d}$ & & $269(1.0)$ & \\
Phenyl glycidyl ether & $33.0^{d}$ & & $269(1.0)$ & \\
Th-1 & 0.65 & $269(1.0)$ & $269(1.0)$ & $270(1.0)$ \\
Thy & 3.53 & $267(1.2)$ & $267(1.2)$ & \\
\hline
\end{tabular}

a Capacity factors by reversed-phase HPLC, $k^{\prime}=\left(t-t_{0}\right) / t_{0}$.

${ }^{b}$ Reagents $(0.1 \mathrm{M} \mathrm{HCl}$ or $0.1 \mathrm{M} \mathrm{NaOH})$ added to an equal volume of sample in water, so that the absorbance is between 0.5 and 1.0 .

c Peak maxima in $\mathrm{nm}$ and $254 / 280 \mathrm{~nm}$ absorbance ratios in parentheses.

d Capacity factor in the solvent system $0.01 \mathrm{M}$ ammonium formate (pH 5.1)-methanol (90:10); flow-rate $1.8 \mathrm{ml} / \mathrm{min}$. 

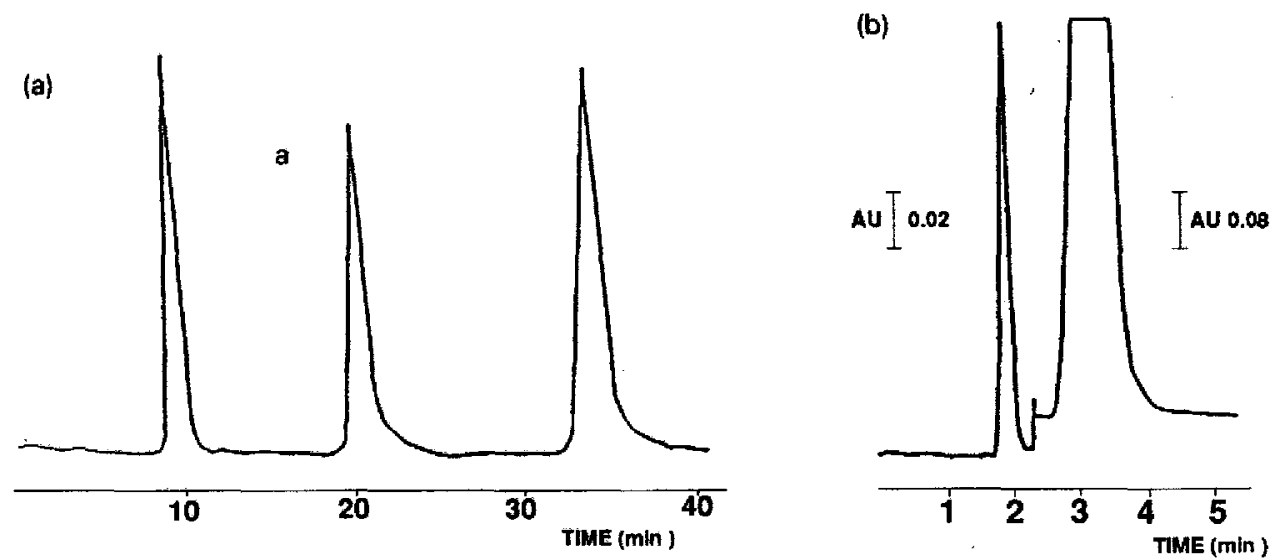

Fig. 1. (a) Analytical reversed-phase HPLC of dAdo-phenyl glycidyl ether reaction mixture. Column, 10 RP-18 (25 cm $\times 4.6 \mathrm{~mm}$ I.D.); eluent, $0.01 \mathrm{M}$ ammonium formate (pH 5.1)-methanol, 90:10) flow-rate, 1.8 $\mathrm{ml} / \mathrm{min}$, (b) Analytical reversed-phase HPLC of Thy-phenyl glycidyl ether reaction mixture. Column, 10 RP-18 (25 cm $\times 4.6 \mathrm{~mm}$ I.D.); eluent, $0.01 \mathrm{M}$ ammonium formate ( $\mathrm{pH}$ 5.1)-methanol, (95:5); flow-rate, 2.0 $\mathrm{ml} / \mathrm{min}$.

For both the 2'-deoxyadenosine-phenyl glycidyl ether mixture and the thymidine phenyl glycidyl ether mixture, the eluents used separated the reaction product from the other components, i.e., unreacted base, phenyl glycidyl ether and phenyl glycidyl ether-diol, which is sometimes formed in minor amounts. The results obtained for the reaction mixtures after 24 and $48 \mathrm{~h}$ are given in Fig. 1a and b and Table II. Adduct formation in the thymidine reaction mixture after 24 and $48 \mathrm{~h}$ was identical. For deoxyadenosine, however, although the analytical HPLC traces of the 24- and 48-h reaction mixtures were identical, preparative isolation of the adduct peak $\left(t_{\mathrm{R}}=\right.$ $27.6 \mathrm{~min}$ ) (Fig. 2) revealed that in the 24-h mixture only a monoalkylated adduct was formed (see mass spectra), whereas in the 48-h mixture mono- and dialkylated adducts were formed and not separated in the present system.

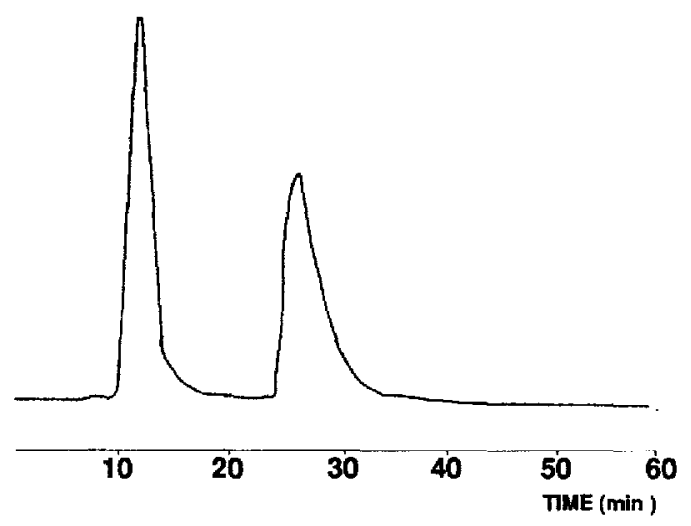

Fig. 2. Preparative reversed-phase HPLC of dAdo-phenyl glycidyl ether reaction mixture. Column, 10 RP-18 (25 cm $\times 2.2 \mathrm{~cm} \mathrm{I.D.);} \mathrm{eluent,} 0.01 M$ ammonium formate (pH 5.1)-methanol, (80:20); flow-rate, 7.2 $\mathrm{ml} / \mathrm{min}$. 
Thin-layer chromatography and preparative circular thin-layer chromatography

As a preliminar screening technique and to establish conditions for circular TLC, regular TLC in several solvent systems was tried. The results for the 48-h thymidine and deoxyadenosine reaction mixtures are given in Table III. In the thymidine reaction mixture only one reaction product is detected in all the systems used; in the 24-h 2'-deoxyadenosine reaction mixture one product is formed and in the 48-h mixture in solvent systems II and IV two products are separated.

TABLE III

$R_{F}$ VALUES OF 48 -h THYMIDINE AND $2^{\prime}$-DEOXYADENOSINE REACTION MIXTURES

\begin{tabular}{llllllll}
\hline Solvent & dThy & TH-I & dAdo & AD-2 & AD-1 & $\begin{array}{l}\text { Phenyl glycidyl } \\
\text { ether-diol }\end{array}$ & $\begin{array}{l}\text { Phenyl glycidyl } \\
\text { ether }\end{array}$ \\
\hline I & 0.38 & 0.67 & 0.33 & 0.16 & 0.16 & 0.80 & 0.95 \\
II & 0.82 & 0.90 & 0.61 & 0.32 & 0.21 & 0.88 & 1.00 \\
III & 0.79 & 0.79 & 0.69 & 0.60 & 0.60 & 0.79 & 1.00 \\
IV & 0.70 & 0.80 & 0.10 & 0.20 & 0.36 & 0.80 & 0.95 \\
V & & & 0.87 & 0.92 & 0.92 & 0.95 & 1.00 \\
\hline
\end{tabular}

As TLC gave a good separation of the reaction products the technique of centrifugal circular TLC on a Chromatotron instrument was evaluated to obtain pure 2 -deoxynucleoside adducts for subsequent ${ }^{1} \mathrm{H}$ NMR and mass spectral analysis. If an appropriate solvent system can be found, the latter technique provides an elegant and rapid method for the isolation of pure phenyl glycidyl ether adducts. As a separation method elaborated on an analytical TLC plate can in most instances be easily transferred to the centrifugal circular TLC (Chromatotron) system without too large a decrease in efficiency, an analytical TLC system was first elaborated for both reaction mixtures. The results are summarized in Table III.

Some restrictions are imposed on the use of solvent systems in circular TLC. Therefore, mixtures of THF and dichloromethane were tested for preparative purposes.

The thymidine reaction mixture was easy to analyse as two well separated bands could be collected. NMR and MS, discussed below, identified the compound with $R_{F}$ 0.80 as a monoalkylated thymidine adduct. The two $2^{\prime}$-deoxyadenosine adducts were characterized as monoalkylated material (AD-1) and a mixture of mono- and dialkylated material (AD-2). The fact that the second band contained a mixture of mono- and dialkylated material could be explained by the difficulty in the visual resolution of bands with a low $R_{F}$ value in the Chromatotron system. Bands with a high $R_{F}$ value are sharp, in contrast to bands with a low $R_{F}$ value, which tend to be diffuse, rendering a complete separation difficult.

\section{Thymidine adduct}

The ${ }^{1} \mathrm{H}$ NMR data for the thymidine adduct in $\left[{ }^{2} \mathrm{H}_{6}\right]$ dimethyl sulphoxide $\left(\left[{ }^{2} \mathrm{II}_{6}\right] \mathrm{DMSO}\right)$ and of the $2^{\prime}$-deoxyadenosine adduct in $\left[{ }^{2} \mathrm{II}_{4}\right]$ methanol-water (1:1) arc given in Table IV, together with the appropriate reference data. Compared with 
thymidine, additional resonances in the region $\delta=3.88-4.14$ (six protons) and the aromatic region (five protons) indicated the presence of a phenyl glycidyl ether moiety on the pyrimidine ring.

In order to exclude possible alkylation at the sugar hydroxyl functions, the spectra of the phenyl glycidyl ether-thymidine adduct were recorded in $\left[{ }^{2} \mathrm{H}_{6}\right]$ DMSO and $\left[{ }^{2} \mathrm{H}_{6}\right]$ DMSO trifluoroacetic acid (TFA). In the latter spectrum there is a narrowing of the $\mathrm{H}^{\prime}-3$ and $\mathrm{H}^{\prime}-5$ pattern, wich could be explained by the disappearance of the $3 J(\mathrm{H}, \mathrm{OH})$ coupling. This was proof of the presence of an intact $2^{\prime}$-deoxyribofuranosyl moiety. When we considered in more detail the $\mathrm{OH}$ resonances in the $\left[{ }^{2} \mathrm{H}_{6}\right]$ DMSO spectrum, the doublet at $\delta=4.2 \mathrm{ppm}$ could be assigned to $3^{\prime}-\mathrm{OH}$ and the triplet at $\delta 4.95$ to $5^{\prime}-\mathrm{OH}$. Two triplets were found at 5.19 and $5.22 \mathrm{ppm}$, each integrating for one proton. The signal at $\delta=5.22 \mathrm{ppm}$ belongs together with a resonance at $\delta=3.15 \mathrm{ppm}$ (shown by a double irradiation experiment) to an impurity. The resonance signal at $\delta=5.19 \mathrm{ppm}$ was assumed, however, to be built up of two doublets originating from the phenyl glycidyl ether hydroxyl function. The latter observation was substantiated by the observation that the proton resonances of the phenyl glycidyl ether moiety were split, conistent with the occurrence of two different hydrogen bridges, as shown in Fig. 3.
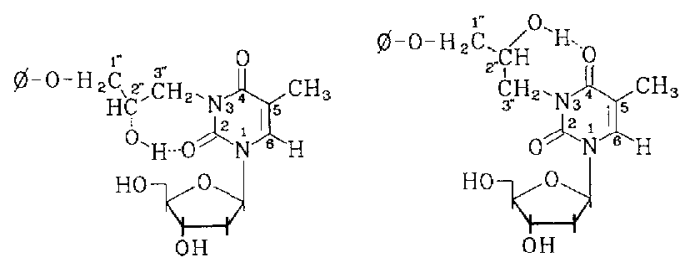

Fig. 3. Possible formation of hydrogen bridges of N-3-(2-hydroxy-3-phenoxypropyl)thymidine. $\varnothing=$ Phenyl.

This was an indication that the reaction between thymidine and phenyl glycidyl ether occurred at N-3 and at the less hindered position of the phenyl glycidyl ether. Because of degeneration of the spin system of $\mathrm{H}_{-1} \mathrm{~A}^{\prime \prime}, \mathrm{H}-1 \mathrm{~B}^{\prime \prime}$ and $\mathrm{H}-2^{\prime \prime}$, their mutual coupling constants could not be measured. For $\mathrm{H}-2^{\prime \prime}, \mathrm{H}-3 \mathrm{~A}^{\prime \prime}$ and $\mathrm{H}-3 \mathrm{~B}^{\prime \prime}$ we observe a downfield shift in the range of $0.37-0.62 \mathrm{ppm}$, caused by the change of linkage from an $\mathrm{OH}$ to the base and another indication that the reaction occurred at $\mathrm{C}-3^{\prime \prime}$ of the glycidyl ether, which confirmed our finding from the $\mathrm{OH}$ resonances. The coupling constant $2 J\left(3 \mathrm{~A}^{\prime \prime}, 3 \mathrm{~B}^{\prime \prime}\right)$ of $12 \mathrm{~Hz}$ in the adduct (Table V) could be attributed to the $\mathrm{C}-2^{\prime \prime}$, C-3" moiety of the glycidyl part by comparison with the coupling constants of phenyl glycidyl ether-diol in ${ }^{2} \mathrm{H}_{2} \mathrm{O}$ solution. We must point to the collapse of the two protons of $\mathrm{C}-1^{\prime \prime}$ for the two modifications, which is acceptable only if the phenoxy-CH2 $\left(1^{\prime \prime}\right)$ part does not belong to one of the supplementary rings caused by the hydrogen bridge.

\section{Adenosine adduct}

The $360-\mathrm{MHz}{ }^{1} \mathrm{H}$ NMR spectrum of the adenosine adduct was recorded in $\left[{ }^{2} \mathrm{H}_{4}\right]$ methanol. Comparison of the chemical shifts of the glycidyl moiety in the adduct with those observed in phenoxypropane-1,2-diol showed an important downfield shift in the range of $0.6-0.7 \mathrm{ppm}$ of the protons on $\mathrm{C}-3^{\prime \prime}$, which indicates that the reaction occurred on the less hindered carbon atom. The assignments of the $1 \mathrm{D}{ }^{1} \mathrm{H}$ NMR 


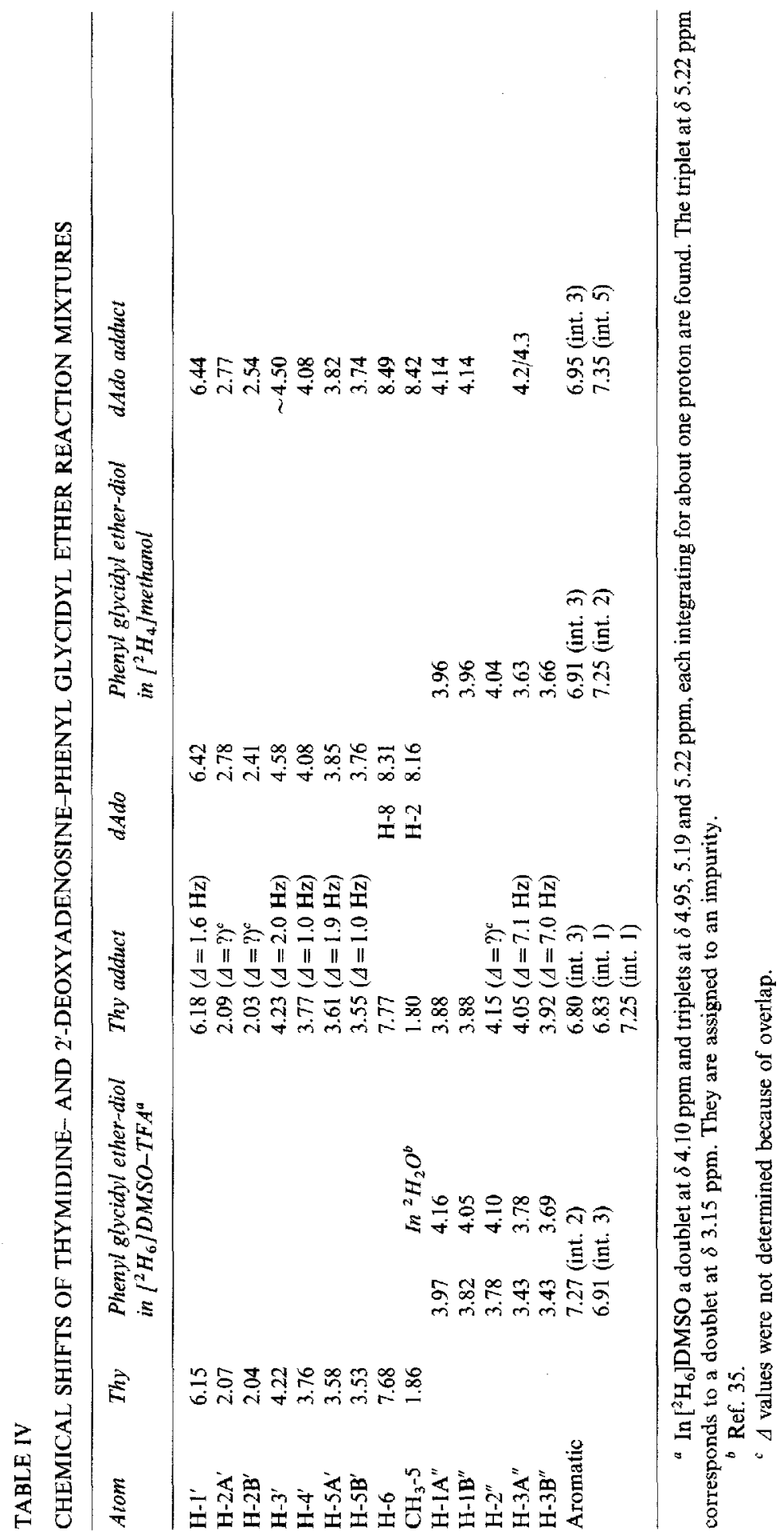


TABLE V

COUPLING CONSTANTS (Hz) OF THYMIDINE- AND 2'-DEOXYADENOSINE-PHENYL GLYCIDYL ETHER REACTION MIXTURES

\begin{tabular}{|c|c|c|c|c|c|c|}
\hline \multirow{2}{*}{$\begin{array}{l}I \\
\qquad{ }^{3} J\left(1^{\prime}, 2 \mathrm{~A}^{\prime}\right)\end{array}$} & \multirow{2}{*}{$\begin{array}{r}d T h y \\
6.5\end{array}$} & \multicolumn{2}{|c|}{ Phenyl glycidyl ether-diol } & \multirow{2}{*}{$\begin{array}{r}\frac{d T h y}{\text { adduct }} \\
\frac{6.4}{}\end{array}$} & \multirow{2}{*}{\begin{tabular}{r}
\multicolumn{1}{c}{ dAdo } \\
6.1
\end{tabular}} & \multirow{2}{*}{$\begin{array}{r}\begin{array}{l}\text { dAdo } \\
\text { adduct }\end{array} \\
6.1\end{array}$} \\
\hline & & & & & & \\
\hline${ }^{3} J\left(1^{\prime}, 2 B^{\prime}\right)$ & 7.0 & & & 6.5 & 5.9 & 5.9 \\
\hline${ }^{2} J\left(2 A^{\prime}, 2 B^{\prime}\right)$ & 13.0 & & & & -13.5 & -13.1 \\
\hline${ }^{3} J\left(2 A^{\prime}, 3^{\prime}\right)$ & 6.5 & & & & $6.8 / 7.7$ & 7.0 \\
\hline${ }^{3} J\left(2 \mathbf{B}^{\prime}, 3^{\prime}\right)$ & 4 & & & & 2.3 & 3.7 \\
\hline${ }^{3} J\left(3^{\prime}, 4^{\prime}\right)$ & 2.7 & & & 2.5 & 3.0 & \\
\hline${ }^{3} J\left(4^{\prime}, 5 A^{\prime}\right)$ & 3.8 & & & 3.8 & 2.9 & 3.6 \\
\hline${ }^{3} J\left(4^{\prime}, 5 \mathbf{B}^{\prime}\right)$ & 3.9 & & & 3.9 & 3.3 & 4.3 \\
\hline${ }^{2} J\left(5 \mathrm{~A}^{\prime}, 5 \mathrm{~B}^{\prime}\right)$ & -11.8 & & $\mathrm{In}^{2} \mathrm{H}_{2} \mathrm{O}$ & -11.9 & -12.3 & -12.2 \\
\hline${ }^{3} J\left(1 \mathrm{~A}^{\prime \prime}, 2^{\prime \prime}\right)$ & & 4.1 & 3.0 & & & \\
\hline${ }^{3} J\left(\mathbf{I B}^{\prime \prime}, 2^{\prime \prime}\right)$ & & 6.1 & 6.0 & & & \\
\hline${ }^{2} J\left(1 \mathrm{~A}^{\prime \prime}, 1 \mathrm{~B}^{\prime \prime}\right)$ & & -9.6 & -9.2 & & & \\
\hline${ }^{2} J\left(2^{\prime \prime}, 3 A^{\prime \prime}\right)$ & & - & 4.4 & 4.0 & & \\
\hline${ }^{3} J\left(2^{\prime \prime}, 3 B^{\prime \prime}\right)$ & & - & 5.6 & 6.0 & & \\
\hline${ }^{2} J\left(3 \mathrm{~A}^{\prime \prime}, 3 \mathrm{~B}^{\prime \prime}\right)$ & & - & -11.6 & -12.0 & & \\
\hline
\end{tabular}

spectrum were confirmed by a spin-lock experiment, yielding both homonuclear Hartmann-Hahn ${ }^{32}$ and rotating frame NOE(ROE) ${ }^{31}$ cross-peaks.

In the ID ${ }^{1} \mathrm{H}$ NMR spectrum, some resonance signals coincide with the water peak in $\left[{ }^{2} \mathrm{H}_{4}\right]$ methanol, making some assignments difficult, but from the connectivities afforded by homonuclear Hartmann-Hahn cross-peaks in the spin-lock experiment, $\mathrm{H}-3^{\prime}$ could be assigned from its connectivity with $\mathrm{H}-4^{\prime}$. From the phenyl glycidyl ether moiety, only the doublet of $\mathrm{H}-1 \mathrm{~A}^{\prime \prime}$ and $\mathrm{H}-1 \mathrm{~B}^{\prime \prime}$ at $\delta=4.14 \mathrm{ppm}$ can be seen. Likewise, with the help of the Hartmann-Hahn cross-peaks in the spin-lock experiment, the hidden resonances for $\mathrm{H}-2^{\prime \prime}$ and $\mathrm{H}-3^{\prime \prime}$ could be traced under the water peak. The assignment of the glycidyl protons was confirmed by an ROE cross-peak between one of the aromatic protons and the doublet of $\mathrm{H}-1 \mathrm{~A}^{\prime \prime}$ and $\mathrm{H}-1 \mathrm{~B}^{\prime \prime}$. We observed an ROE
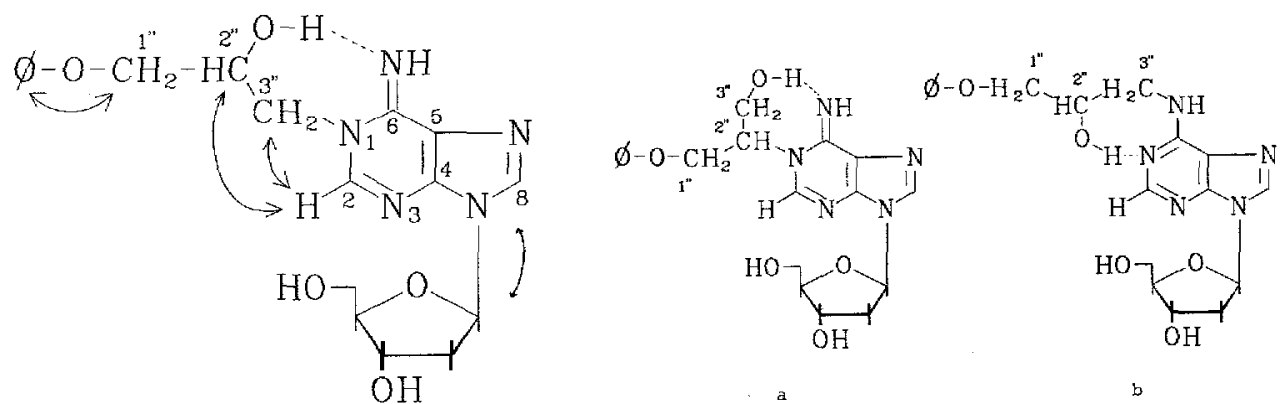

Fig. 4. Proposed structure of main $2^{\prime}$-deoxyadenosine-phenyl glycidyl ether adduct: N-1-(2-hydroxy-3phenoxypropyl)-2'-deoxyadeosine. The arrows show the ROE effects measured.

Fig. 5. Unlikely $2^{\prime}$-deoxyadenosine phenyl glycidyl ether adduct structures: N-6 alkylation products. 
effect between one of the purine ring protons and $\mathrm{H}-1^{\prime}$ of the sugar moiety. When we took the $\mathrm{H}-\mathrm{I}^{\prime}-\mathrm{H}-2$ and $\mathrm{H}-\mathrm{I}^{\prime}-\mathrm{H}-8$ distances into consideration and took into account that only one cross-peak was observed, we may accept an ROE contact between $\mathrm{H}-1$ and $\mathrm{H}-8$. This hypothesis was substantiated by the observation of ROE cross-peaks between the protons on $\mathrm{C}-2^{\prime \prime}$ and $\mathrm{C}-3^{\prime \prime}$ with $\mathrm{H}-2$ of the base. An ROE effect between $\mathrm{H}-8$ and the protons on the phenyl glycidyl part is excluded.

The observations discussed above can only be explained if the reaction has occurred between N-1 and the less hindered epoxide carbon atom of the phenyl glycidyl moiety.

The ROE effects are show in Fig. 4. Indeed, if the reaction had occurred between $\mathrm{N}-1$ and $\mathrm{C}-2^{\prime \prime}$, an ROE effect between $\mathrm{H}-2$ and $\mathrm{H}-3^{\prime \prime}$ would have been impossible and an NOE effect between $\mathrm{H}-2$ and $\mathrm{H}_{-1} \mathbf{1}^{\prime \prime}$ must be expected (Fig. 5a). The occurrence of an ROE contact between $\mathrm{H}-3^{\prime \prime}$ and $\mathrm{H}-2^{\prime \prime}$ with $\mathrm{H}-2$ implies that the reaction did not occur at the $\mathrm{NH}$ on $\mathrm{C}-6$. In this instance an ROE contact between $\mathrm{H}-2$ and $\mathrm{H}-2^{\prime \prime}$ and also between $\mathrm{H}-2$ and the $\mathrm{H}-3^{\prime \prime}$ resonances is unlikely (Fig. 5b). From the ROE data there is little doubt that the reaction occurred between N-1 and C-3" (Fig. 4).

The DCI (ammonia) mass spectrum of the phenyl glycidyl ether adduct of thymidine was characterized by the presence of a protonated molecule $[\mathrm{MH}]^{+}$at $\mathrm{m} / \mathrm{z}=$ $393(100 \%)$. Fragment ions were detected at $m / z=277(72 \%), m / z=188(84 \%), m / z$ $=116(36 \%)$ and $m / z=134(38 \%)$. The ion at $m / z=277$ can be assigned to the base protonated ion $\left(\mathrm{BH}_{2}\right)^{+}$as a result of a rearrangement process involving the cleavage of the anomeric $\mathrm{C}-1^{\prime}-\mathrm{N}$ bond ${ }^{36}$ and subsequent loss of a molecule of phenol results in the formation of $m / z=183$. The fragment ions at $m / z=116$ and 134 can be attributed to the sugar protonated ion, $[\mathrm{S}-\mathrm{H}]^{+}$and $[\mathrm{S}-\mathrm{H}] \cdot \mathrm{NH}_{\mathbf{4}}^{+}$.
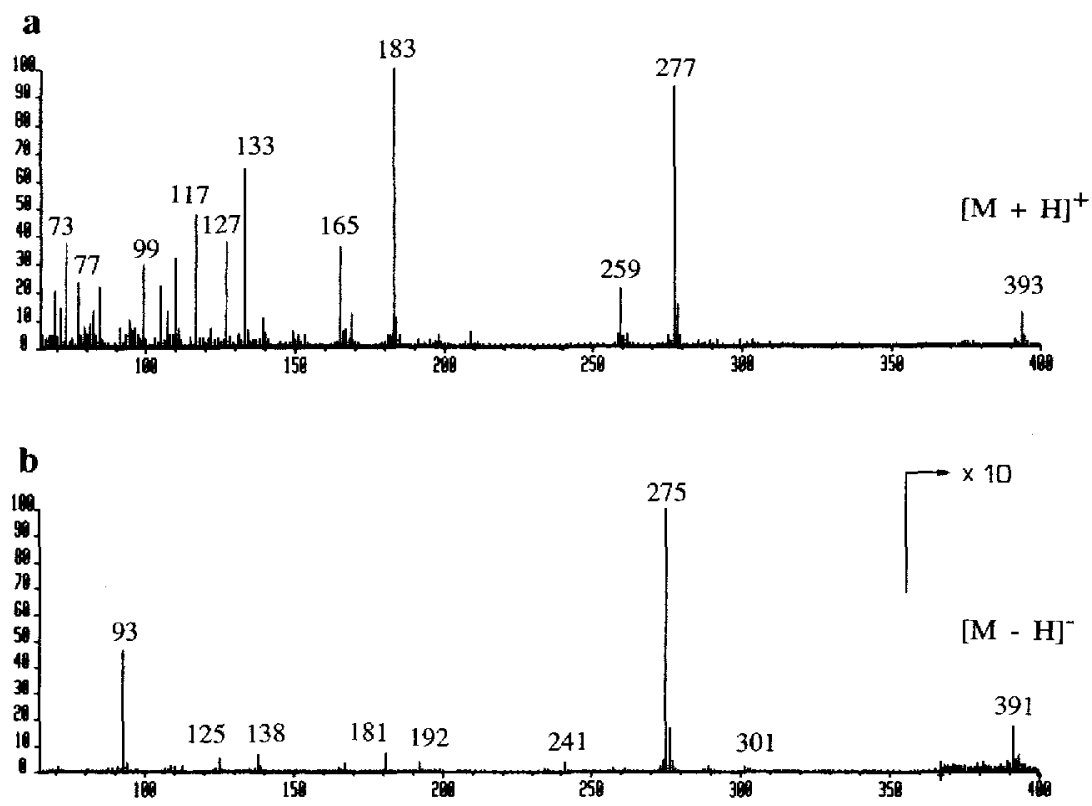

Fig. 6. FAB mass spectra of the tymidine-phenyl glycidyl ether adduct: (a) positive and (b) negative ion mode. 
With the phenyl glycidyl ether adduct of $2^{\prime}$-deoxyadenosine, structurally analogous ions were observed, although $[\mathrm{MH}]^{+}$was less abundant. The following ions were detected: $m / z=402\left([\mathrm{MH}]^{+}, 15 \%\right), m / z=286\left(\left[\mathrm{BH}_{2}\right]^{+}, 100 \%\right), m / z=192$ $\left(\left[\mathrm{BH}_{2}-\right.\right.$ phenol $\left.^{+}, 20 \%\right), m / z=116(35 \%)$ and $m / z=134(48 \%)$. In both instances the typical rearrangement ions for 2 -deoxynucleosides, i.e., $[\mathrm{B}+30]^{+}$and $[\mathrm{B}+28]^{+}$ were absent.

Analysis of the phenyl glycidyl ether adduct formation for $2^{\prime}$-deoxyadenosineafter a prolonged reaction time $(48 \mathrm{~h})$ revealed the presence of additional ions at $\mathrm{m} / \mathrm{z}=$ 552 and 436 . These are suggestive of a bisalkylated 2 -deoxyadenosine. This was unequivocally proved with the aid of FAB-MS-MS.

The FAB mass spectra (positive-ion mode) show a remarkable similarity with the DCI spectra. The positive FAB mass spectrum of the phenyl glycidyl ether adduct of thymidine yields a protonated molecule $[\mathrm{MH}]^{+}$at $m / z=393$ (Fig. 6a). The intense fragment ions at $m / z=277$ and 117 are formed by cleavage of the $\mathrm{N}$-glycosidic bond and correspond to the chemically modified base $\left[\mathrm{BH}_{2}\right]^{+}$and the sugar moiety $[\mathrm{S}]^{+}$, respectively. The $\left[\mathrm{BH}_{2}\right]^{+}$ion further decomposes by loss of even-electron species, giving rise to fragments at $m / z=259$ (loss of $\mathrm{H}_{2} \mathrm{O}$ ), $m / z=183$ (loss of phenol), $m / z=165$ (combined loss of $\mathrm{H}_{2} \mathrm{O}$ and phenol) and $m / z=127$ (loss of phenyl glycidyl ether). Additional structural information is obtained from the fragmentation of the 2-hydroxy-3-phenoxypropyl group (R) (e.g., $\mathrm{R}^{+}$at $m / z=151$, [R $\left.-\mathrm{H}_{2}\right]$ at $m / z=149$, $\left[\mathrm{R}-\mathrm{H}_{2} \mathrm{O}\right]^{+}$at $m / z=133$ and $\left[\mathrm{R}-\mathrm{C}_{2} \mathrm{H}_{4} \mathrm{O}\right]^{+}$at $\left.m / z=107\right)$.

The FAB mass spectrum (negative ion mode) of the phenyl glycidyl ether adduct of thymidine shows an $[\mathrm{M}-\mathrm{H}]^{+}$ion at $m / z=391$ and a fragmentation pattern similar to that obtained in the positive ion mode (Fig. 6b). Only limited additional structural information is gained. The abundant ion at $m / z=93$ corresponds to the phenolate anion. The ion at $m / z=192$ can be rationalized by a retro-Diels-Alder (RDA) rearrangement with retention of the negative charge on the side-chain (Fig. 7). This fragmentation provides evidence that the alkylation takes place at the $\mathrm{N}-3$ position.

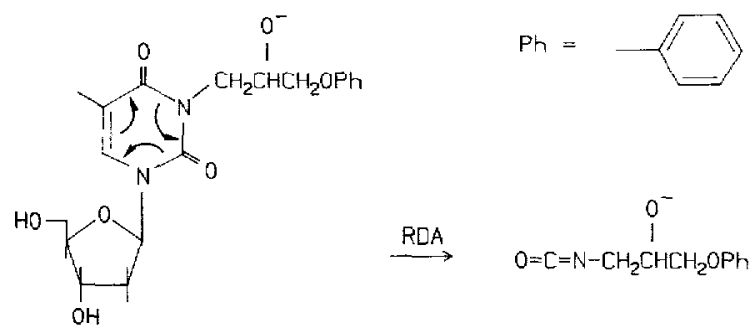

$m / z \quad 391$

$m / z 192$

Fig. 7. Retro-Diels-Alder rearrangement of phenyl glycidyl ether adduct of thymidine.

With the phenyl glycidyl ether adducts of the 48-h reaction mixture of $2^{\prime}$-dcoxyadenosine, the situation is more complex because the isolated fraction consists of a mixture of the mono- and bisalkylated 2'-deoxynucleosides. In the positive FAB mass spectrum, the $[\mathrm{MH}]^{+}$ions are detected at $m / z=402$ and 552, respectively (Fig. 8 a). Because a mixture is involved, it is impussible to distinguish which fragment ions are associated with which protonated molecules. An additional problem is that 

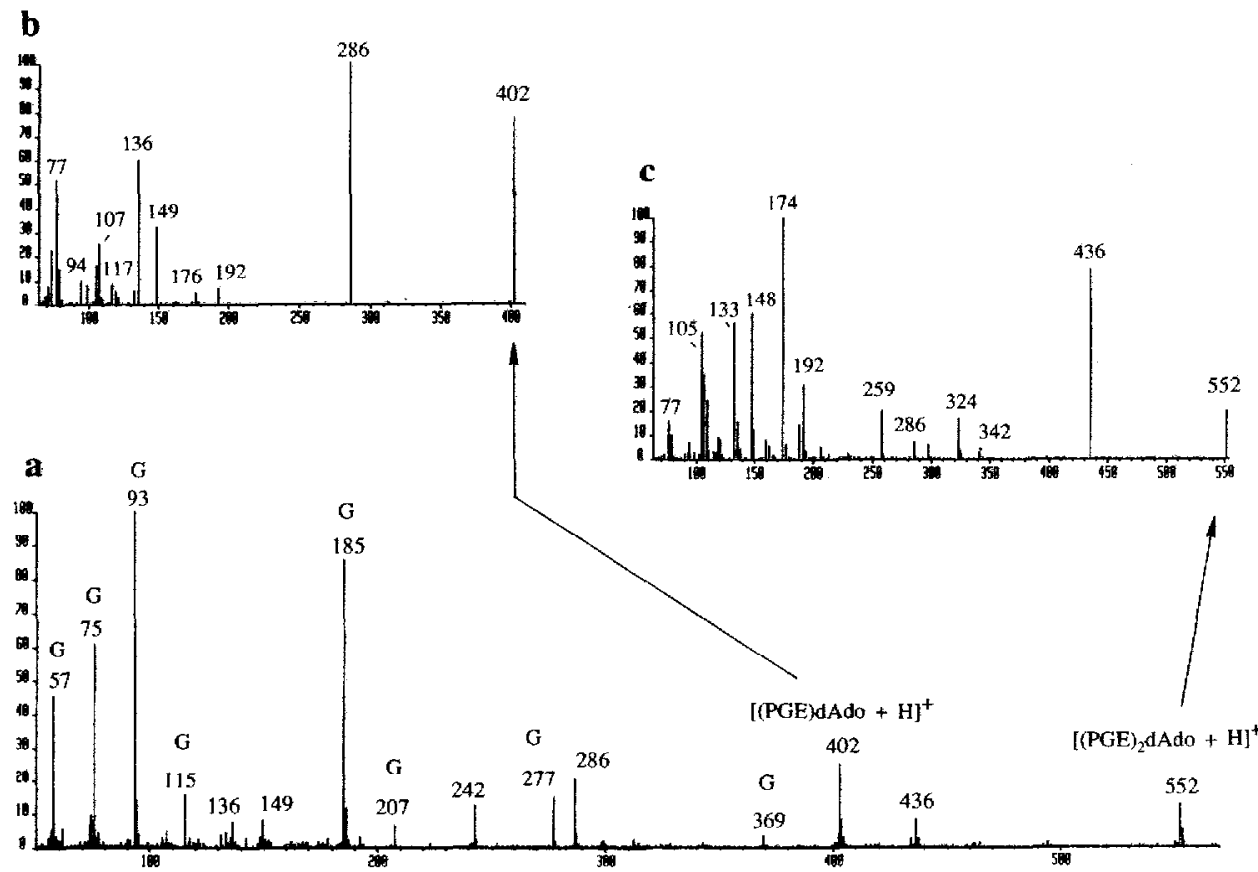

Fig. 8. (a) FAB mass spectrum (positive ion mode) of 2'-deoxyadenosine-phenyl glycidyl ether adducts of 48-h reaction mixture; ions originating from the glycerol matrix are labelled $\mathrm{G} ;(\mathrm{b}, \mathrm{c})$ daughter ion spectra (MS-MS) of the ions at (b) $m / z=402$ and (c) $m / z=552$ obtained by $C A D$ at a collision energy of $30 \mathrm{eV}$ and a gas pressure of $10^{-5}$ mbar.

low-abundance fragment ions are obscured by the chemical noise originating from the matrix (see glycerol peaks labelled $G$ in the spectrum). To overcome these two often-encountered drawbacks of FAB-MS, we used collisionally activated decomposition in combination with tandem mass spectrometry. With the FAB-MS-CADMS techique an ion of interest is selected (MS-I), fragmented by collisionally activated decomposition and a daughter ion spectrum is taken of the fragments (MS-II). In this way, chemical noise is largely eliminated, stable fragment ions are induced to decompose and, with a mixture, parent-daughter relationships can be determined.

The daughter ion spectrum of the $[\mathrm{MH}]^{+}$ion $(\mathrm{m} / \mathrm{z}=402)$ of monoalkylated $2^{\prime}$-deoxyadenosine (Fig. 8 b) is dominated by the $\mathrm{BH}_{2}^{+}$ion at $m / z=286$, formed by loss of the sugar residue with concomitant proton transfer. The other fragments result from the combined loss of the sugar and phenol $(\mathrm{m} / \mathrm{z}=192)$, phenol and $\mathrm{H}_{2} \mathrm{O}(\mathrm{m} / \mathrm{z}=174)$ or phenyl glycidyl ether $(m / z=136)$. Abundant ions at $m / z=149,133,107,105$ and 77 originate from fragmentation of and charge retention on the 2-hydroxy-3-phenoxypropyl group. In the CAD mass spectrum of the $[\mathrm{MH}]^{+}$ion $(m / z=552)$ of bisalkylated 2'-deoxyadenosine (Fig. 8c), a similar fragmentation behaviour is observed. The absence of the daughter ion at $m / z=402$, corresponding to the $[\mathrm{MH}]^{+}$ ion of the monoalkylated derivative, clearly demonstrates that the peak at $m / z=402$ in the normal FAB mass spectrum (Fig. 8a) is due to the monoalkylated product 


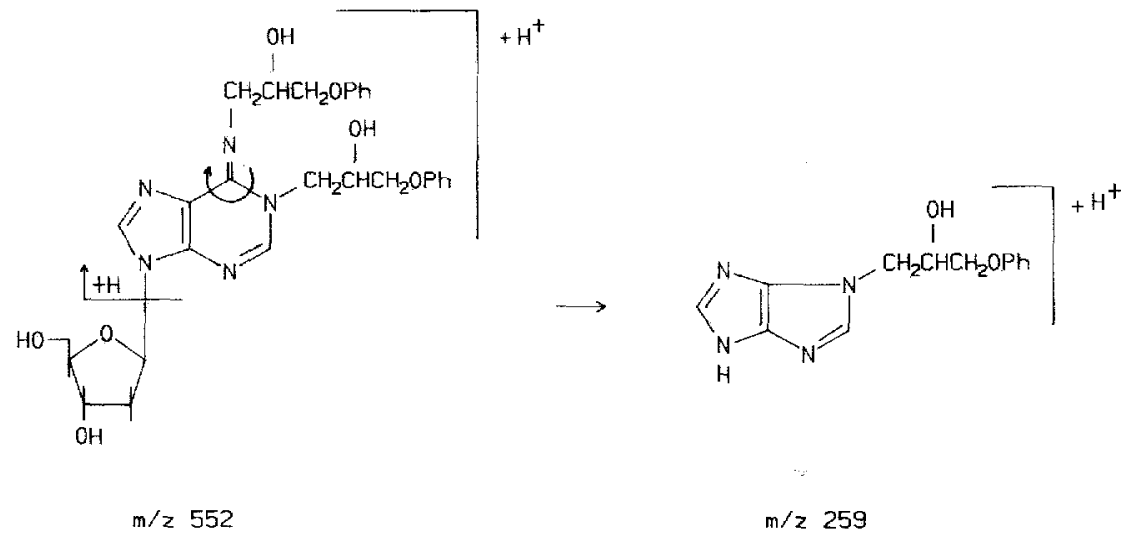

Fig. 9. CAD mass spectral fragmentation pattern of dialkylated $2^{\prime}$-deoxyadenosine.

occurring together with the bisalkylated derivative in the isolated fraction. Another point of interest is the presence of the ion at $m / z=259$ in the CAD mass spectrum, which gives information about the position of phenyl glycidyl ether-base bonds, as outlined in Fig. 9.

From these results, it is clear that FAB in combination with MS-MS provides a valuable approach to the characterization of phenyl glycidyl ether-nucleoside adducts. In addition, FAB-MS CAD-MS yields complementary structural information compared with FAB-MS alone. A more detailed discussion of the collisionally activated decomposition of gas-phase $[\mathrm{MH}]^{+}$and $[\mathrm{M}-\mathrm{H}]^{-}$ions of phenyl glycidyl ether-nucleoside adducts will be reported elsewhere ${ }^{37}$.

\section{CONCLUSIONS}

Circular preparative TLC proved to be a rapid separation method for the isolation of simple 2'-deoxynucleoside-phenyl glycidyl ether adduct mixtures such as thymidine-phenyl glycidyl ether. However, when the reaction mixtures are more complicated, such as in the 48-h deoxyadenosine-phenyl glycidyl ether mixture, resolution can be a problem. Preparative HPLC on an RP-18 reversed-phase column was efficient for the isolation of the main adducts of the thymidine- and deoxyadenosine-phenyl glycidyl ether mixtures. HPLC with photodiode-array detection proved to be an excellent method for the preliminary itentification of the adducts. The structures already suggested by UV data for N-3(2-hydroxy-3-phenoxypropyl)thymidine and N-1-(2-hydroxy-3-phenoxypropyl)-2'-deoxyadenosine were confirmed by the additional NMR and mass spectral data. These adducts and the methods developed in this study will be used for the possible detection of DNA-phenyl glycidyl ether adducts.

\section{ACKNOWLEDGEMENTS}

J.E.S. acknowledges support by grant ROI ES 03345 from the National Institute of Environmental Health Sciences DHHS. The typing of the manuscript by C. 
Rawoens is gratefully acknowledged. Professor Vandewalle is gratefully acknowledged for the use of the NMR facilities.

\section{REFERENCES}

1 H. Nishioka and H. Ohtani, Mutat. Res., 54 (1978) 247-251.

2 E. J. Greene, M. A. Friedman, J. A. Sherrod and A. J. Salerno, Mutat. Res., 67 (1979) 9-19.

3 M. J. Wade, J. W. Moyer and C. H. Hine, Mutat. Res., 66 (1979) 367-371.

4 L. Fishbein, Sci. Total Environ., 17 (1981) 97-110.

5 K. Hemminki, K. Falck and H. Vainio, Arch. Toxicol, 46 (1980) 277-285.

6 E. D. Thompson, W. J. Coppinger, C. E. Piper, N. McCarroll, T. J. Oberly and D. Robinson, Mutat. Res., 90 (1981) 213-231.

7 C. E. Voogd, J. J. Van der Stel and J. J. A. A. Jacobs, Mutat, Res., 89 (1981) 169-282.

8 A. F. Frost ad M. S. Legator, Mutat. Res., 102 (1982) 193-200.

9 K. Sugiura, M. Goto, Chem. Biol. Interact., 45 (1983) 153-169.

10 J. P. Seiler, Mutat. Res., 135 (1984) 159-167.

11 D. A. Canter, E. Zeiger, S. Haworth, T. Lawlor, K. Mortelman and W. Speck, Mutat. Res., 172 (1986) $105-138$.

12 S. H. Neau, B. H. Hooberman, S. W. Frante and J. E. Sinsheimer, Mutat. Res., 93 (1982) 297-304.

13 L. B. Rosman, P. K. Chakraborty, E. A. Messerly and J. E. Sinsheimer, Mutat. Res., 206 (1988) 115-126.

14 J. B. Terrill, K. P. Lee, R. Culik and G. L. Kennedy, Jr., Toxicol. Appl. Pharmcol., 64 (1982) 204-212.

15 E. B. Whorton, Jr., T. G. Pullin, A. F. Frost, A. Onofre, M. S. Legator and D. S. Folse, Mutat. Res., 124 (1983) 225-233.

16 J. P. Seiler, Chem. Biol. Interact, 51 (1984) 347-356.

17 J. B. Terrill and K. P. Lee, Toxicol. Appl. Pharmacol., 42 (1977) 263-269.

18 J. Hopkins, Food Chem. Toxicol., 22 (1984) 780-783.

19 NIOSH, Criteria for a Recommended Standard, Occupational Exposure to Glycidyl Ethers, U.S. Department of Health, Education and Welfare, Public Health Service, Center for Disease Control, National Institute for Occupational Safety and Healh, Cincinnati, OH, 1978.

20 H. P. Stein, N. A. Leidel, J. M. Lane, Am. Ind. Assoc. J., 40 (1979) A36-A51.

21 D. R. Wade, S. A. Airy, J. E. Sinsheimer, Mutat. Res., 58 (1978) 217-223.

22 S. W. Frantz and J. E. Sinsheimer, Mutat. Res., 90 (1981) 67-78.

23 S. W. Frant7, F. Van en Feckhout, J. F. Sinsheimer, M. Yashihare and M. Koreeda, Toxicol. Lett., 25 (1985) $265-271$.

24 L. B. Rosman, V. G. Beylin, V. Gaddami, B. H. Hooberman and J. E. Sinsheimer, Mutat. Res., 171 (1986) 63-70.

25 L. B. Rosman, V. Gaddamidi and J. E. Sinsheimer, Mutat. Res., 189 (1987) 189-204.

26 Z. Djuric and J. E. Sinsheimer, Chem. Biol. Interact., 50 (1984) 219-231.

27 Z. Djuric and J. E. Sinsheimer, Chem. Biol. Interact., 52 (1984) 243-253.

28 Z. Djuric, B. H. Hooberman, L. Rosman and J. E. Sinsheimer, Environ. Mutat., 8 (1986) 369-383.

$29 \mathrm{~K}$. Hemminki and H. Vainio, in B. Holmstedt, R. Lauwereys, M. Mercier and M. Roberfroid (Editors), Mechanism of Toxicity and Hazard Evaluation, Elsevier/North-Holland, Amsterdam, 1980, pp. $241-243$.

30 E. Van den Eeckhout, P. De Moerloose and J. E. Sinsheimer, J. Chromatogr., 318 (1985) 343349.

31 A. A. Bothner-By, R. L. Stephens, J. M. Lee, C. D. Warren and R. W. Jeanloz, J. Am. Chem. Soc., 106 (1984) $811-813$.

32 A. Bax, D. G. Davies, J. Magn. Reson., 65 (1985) 355-360.

33 A. E. Derome, Modern Techniques for Chemistry Research, Pergamon, Oxford, 1987, p. 83.

34 B. Singer, in G. D. Fasman (Editor), CRC Handbook of Biochemistry and Molecular Biology, CRC Press, Cleveland, OH, 1975, pp. 409-447.

35 A. De Bruyn, D. De Kenkeleire, E. Van den Feckhout and W. Raeyens, Bull Soc. Chim. Relg., 92 (1983) $743-746$.

36 J. A. McCloskey, J. Am. Chem. Soc, 97 (1975) 3436-3444.

37 J. Claereboudt, E. Van den Eeckhout, E. Esmans, W. Baeten and M. Claeys, Biomed. Environ. Mass Spectrom., in preparation. 